\title{
Clinical, electrical, and echocardiographic characteristics of patients with advanced interatrial block
}

\author{
Características clínicas, eléctricas y ecocardiográficas de los pacientes con bloqueo \\ interauricular avanzado
}

\author{
Delicia Gentille-Lorente ${ }^{1 *}$ and Teresa Salvadó-Usach ${ }^{2}$ \\ ${ }^{1}$ Department of Cardiology; ${ }^{2}$ Department of Anatomical Pathology, Hospital de Tortosa Verge de la Cinta IISPV. Tortosa, Tarragona, Spain
}

Bachmann's bundle is integrated with a set of specialized parallel myocardial fibers and accounts for $80-85 \%$ of interatrial conduction. It runs along the anterosuperior atrial walls and its compromise leads to interatrial block (IAB), which can be: (a) partial ( $p-I A B)$ if conduction is delayed (on ECG, it produces a $P$-wave $\geq 120 \mathrm{~ms}$ ) or (b) advanced (a-IAB) if conduction is completely interrupted and left atrial (LA) depolarization occurs in the retrograde caudocranial direction ( $P$ wave is $\geq 120 \mathrm{~ms}$ and biphasic \pm in lower leads II, III, and VF) 1 . a-IAB causes electrical and mechanical atrial dysfunction, which favors the development of "atrial fibrotic myopathy"2,3; fibrosis favors blood stasis and intra-atrial thrombosis (especially in the appendage $)^{4}$, as well as the development of supraventricular arrhythmias such as flutter (typical and atypical), and especially atrial fibrillation (AF): the so-called Bayés syndrome ${ }^{3-8}$. There is evidence that a-IAB is an atrial morphofunctional dysfunction marker and a predictor of events such as AF or flutter (de novo or relapses after cardioversion or ablation), embolic cerebrovascular accident (CVA), and heart failure ${ }^{3-10}$. IAB pathogenesis is not fully known, but its genesis involves degenerative, ischemic, infiltrative, and inflammatory factors (age is the most determining factor); consequently, it may appear that an underlying heart disease exists or not, regardless of the LA size, although it usually occurs in dilated LAs; it can be intermittent and frequency dependent (second-degree IAB) and even reversible, as well as atrial electrical remodeling. The prevalence of IAB increases exponentially with age, and it is high in the general population (59\% in those older than 60 years) and in different patient populations (41-48\%).

The purpose of this study was to clinically, electrically, and echocardiographically characterize patients with $I A B$, and analyze its relationship with $A F / f l u t t e r$ and CVA. A descriptive, observational, retrospective protocol was designed that included consecutive patients, of legal age, who attended a high-resolution cardiology clinic (visits with electrocardiogram and echocardiogram) over a 3-year period; all of them were in normal sinus rhythm during the visit. Sixty-three cases of a-IAB were identified on ECG and, therefore, a similar sample of consecutive patients with p-IAB (Fig. 1) and without IAB was selected, which yielded a total sample of 165 patients for the study. The analyzed variables were obtained from the computerized medical records and from patient visits (electrocardiographic and echocardiographic parameters). Using SPSS 19.0, a descriptive analysis was carried out (which expressed the results of quantitative variables as the mean and standard deviation, and those of qualitative variables as percentage), as well as a bivariate (using the Chi-square test,

\section{Correspondence:}

*Delicia Gentille-Lorente

E-mail: dgentile.ebre.ics@gencat.cat
Date of reception: 29-05-2019

Date of acceptance: 06-02-2020 DOI: 10.24875/ACME.M21000184
Available online: 25-05-2021

Arch Cardiol Mex (Eng). 2021;91(1):124-127 www.archivoscardiologia.com 2604-7063 / @ 2020 Instituto Nacional de Cardiología Ignacio Chávez. Published by Permanyer. This is an open access article under the CC BY-NC-ND license (http://creativecommons.org/licenses/by-nc-nd/4.0/). 
Table 1. Characteristics of the patients without $I A B$, with partial $I A B$, and with advanced $I A B$

\begin{tabular}{|c|c|c|c|c|}
\hline & $\begin{array}{l}\text { Normal patients } \\
\quad(n=52)\end{array}$ & $\begin{array}{c}\text { Partial IAB } \\
(\mathrm{n}=50)\end{array}$ & $\begin{array}{c}\text { Advanced } \\
\text { IAB (n = 63) }\end{array}$ & p-value \\
\hline Age (years), $\bar{X} \pm S D$ & $59.8 \pm 13.3$ & $66.9 \pm 11.4$ & $76.4 \pm 8,2$ & $<0.0001$ \\
\hline Age $\geq 65$ years $n(\%)$ & $22(42.3)$ & $33(66.0)$ & $57(90.5)$ & $<0.0001$ \\
\hline Male gender, $\mathrm{n}(\%)$ & $25(48.1)$ & $32(64.0)$ & $41(65.1)$ & 0.132 \\
\hline $\begin{array}{l}\text { Medical history } \\
\text { Hypertension, } \mathrm{n}(\%) \\
\text { Diabetes mellitus, } \mathrm{n}(\%) \\
\text { Dyslipidemia, } \mathrm{n}(\%) \\
\text { Smoking and former smoking, } \mathrm{n}(\%) \\
\text { Body mass index }\left(\mathrm{kg} / \mathrm{m}^{2}\right), \overline{\mathrm{X}} \pm \mathrm{SD} \\
\text { Obesity }\left(\mathrm{BMI} \geq 30 \mathrm{~kg} / \mathrm{m}^{2}\right), \mathrm{n}(\%) \\
\text { Glomerular filtration }(\mathrm{mL} / \mathrm{min}), \overline{\mathrm{X}} \pm \mathrm{SD} \\
\text { Stage } \geq 2 \text { chronic kidney disease }(\mathrm{GF}<90 \mathrm{~mL} / \mathrm{min}), \mathrm{n}(\%) \\
\text { Stage } \geq 3 \text { chronic kidney disease }(\mathrm{GF}<60 \mathrm{~mL} / \mathrm{min}), \mathrm{n}(\%) \\
\text { COPD, } \mathrm{n}(\%) \\
\text { Confirmed OSAHS or snoring + apneas } \\
\text { Ischemic heart disease, } \mathrm{n}(\%) \\
\text { AF/flutter, } \mathrm{n}(\%) \\
\text { Cerebrovascular accident, } \mathrm{n}(\%) \\
\text { Stroke, } \mathrm{n}(\%) \\
\text { Transient ischemic attack, } \mathrm{n}(\%)\end{array}$ & $\begin{array}{c}28(53.8) \\
7(13.5) \\
31(59.6) \\
19(36.5) \\
27.9 \pm 4.7 \\
18(34.6) \\
88.7 \pm 23.3 \\
22(43.1) \\
4(7.7) \\
5(9.6) \\
8(15.4) \\
5(9.6) \\
22(42.3) \\
0(0.0) \\
0(0.0) \\
0(0.0)\end{array}$ & $\begin{array}{c}33(66.0) \\
5(10.0) \\
33(66.0) \\
24(48.0) \\
29.0 \pm 4.3 \\
21(42.0) \\
79.2 \pm 19.1 \\
34(68.0) \\
6(12.0) \\
2(4.0) \\
6(12.0) \\
10(20.4) \\
15(30.0) \\
1(2.0) \\
1(2.0) \\
0(0.0)\end{array}$ & $\begin{array}{c}55(87.3) \\
24(38.1) \\
47(74.6) \\
21(33.3) \\
30.2 \pm 5.2 \\
31(52.5) \\
70.5 \pm 23.2 \\
50(79.4) \\
20(32.3) \\
9(14.3) \\
8(13.6) \\
14(22.2) \\
17(27.0) \\
10(15.9) \\
8(12.7) \\
2(3.2)\end{array}$ & $\begin{array}{c}<0.0001 \\
<0.0001 \\
0.228 \\
0.261 \\
0.045 \\
0.159 \\
<0.0001 \\
<0.0001 \\
0.001 \\
0.186 \\
0.883 \\
0.177 \\
0.194 \\
\text { na } \\
\text { na } \\
\text { na }\end{array}$ \\
\hline $\begin{array}{l}\text { Electrocardiogram } \\
\text { Atrioventricular block, n (\%) } \\
\text { Complete bundle branch block, n (\%) } \\
\text { Anterior or posterior fascicular block, n (\%) } \\
\text { Positive Cornell index, n (\%) } \\
\text { Positive Sokolow-Lyon index, n (\%) }\end{array}$ & $\begin{array}{l}2(3.8) \\
3(5.8) \\
5(9.6) \\
2(3.8) \\
1(1.9)\end{array}$ & $\begin{array}{l}3(6.0) \\
10(20.0) \\
9(18.0) \\
6(12.0) \\
3(6.0)\end{array}$ & $\begin{array}{l}20(31.7) \\
13(20.6) \\
18(29.5) \\
8(12.7) \\
4(6.3)\end{array}$ & $\begin{array}{c}<00001 \\
0.057 \\
0.225 \\
0.225 \\
0.493\end{array}$ \\
\hline 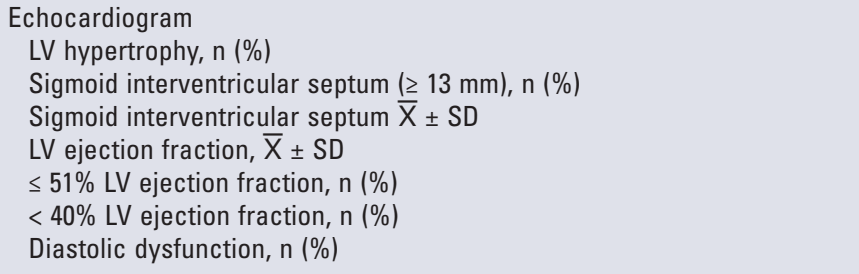 & $\begin{array}{c}7(13.7) \\
7(13.5) \\
13.6 \pm 2.1 \\
61.75 \pm 7.06 \\
2(3.8) \\
0(0.0) \\
15(30.0)\end{array}$ & $\begin{array}{c}10(20.0) \\
10(20.0) \\
15.0 \pm 2.6 \\
57.5 \pm 2.2 \\
11(22.0) \\
3(6.0) \\
19(40.4)\end{array}$ & $\begin{array}{c}16(28.6) \\
16(25.4) \\
16.3 \pm 2.5 \\
60.7 \pm 11.1 \\
7(12.5) \\
4(7.1) \\
38(71.7)\end{array}$ & $\begin{array}{c}0.166 \\
0.281 \\
0.058 \\
0.103 \\
0.022 \\
0.159 \\
<00001\end{array}$ \\
\hline $\begin{array}{l}\text { Diastolic dysfunction, } \mathrm{n}(\%) \\
\text { No } \\
\text { Mild } \\
\geq \text { Moderate }\end{array}$ & $\begin{array}{c}35(70.0) \\
11(22.0) \\
4(8.0)\end{array}$ & $\begin{array}{c}28(59.6) \\
14(29.8) \\
5(10.6)\end{array}$ & $\begin{array}{l}15(28.3) \\
25(47.2) \\
13(24.5)\end{array}$ & $<00001$ \\
\hline LV 4 C area $\left(\mathrm{cm}^{2}\right), \bar{X} \pm S D$ & $18.6 \pm 4.0$ & $21.5 \pm 4.9$ & $23.3 \pm 4.7$ & $<00001$ \\
\hline LA indexed biplane volume $\left(\mathrm{mL} / \mathrm{cm}^{2}\right), \bar{X} \pm S D$ & $30.0 \pm 8.5$ & $37.8 \pm 11.0$ & $39.5 \pm 11.8$ & 0.002 \\
\hline Dilated LA, n (\%) & $16(30.8)$ & $33(66.0)$ & $44(78.6)$ & $<00001$ \\
\hline Mitral annulus calcification, $\mathrm{n}(\%)$ & $3(5.8)$ & $3(6.0)$ & $2(21.8)$ & 0.011 \\
\hline$\geq$ Moderate left valve disease, $n(\%)$ & $8(15.4)$ & $10(20.0)$ & $12(19.0)$ & 0.812 \\
\hline Relevant mitral valve disease & $5(9.6)$ & $6(12.0)$ & 7 (11.1) & 0.926 \\
\hline
\end{tabular}

COPD: Chronic Obstructive Pulmonary Disease; IAB: interatrial block; LA: left atrium; LV: left ventricle; na: not applicable; OSAHS: Obstructive Sleep Apnea-Hypopnea Syndrome.

Fisher's exact test, Student's t-test, and Mann-Whitney's U-test) and a multivariate analysis; the level of significance was established at $p<0.05$.
Bivariate analysis between the three groups of patients yielded the results shown in Table 1. The strong relationship detected between IAB and age, 


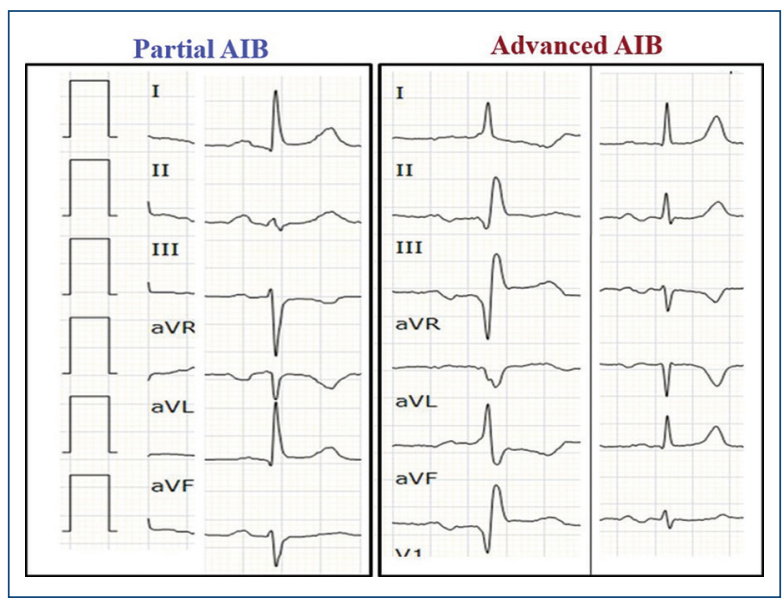

Figure 1. Left panel: ECG horizontal leads of a patient with partial IAB. Right panel: ECG horizontal leads of two patients with advanced IAB.

Table 2. Variables related to the risk for developing advanced IAB

\begin{tabular}{|l|c|c|c|}
\hline & OR & IC 95\% & p-value \\
\hline Age $\geq 65$ years & 6.1 & $1.6-23.7$ & 0.009 \\
\hline Diabetes mellitus & 6.1 & $2.1-17.8$ & 0.001 \\
\hline LA dilation & 6.0 & $2.0-17.4$ & 0.001 \\
\hline Diastolic dysfunction & 3.1 & $1.3-7.7$ & 0.013 \\
\hline
\end{tabular}

Cl: confidence interval; IAB: interatrial block; LA: left atrium; OR: odds ratio.

high blood pressure, diabetes mellitus, chronic kidney disease, first-degree atrioventricular block, diastolic dysfunction (particularly if it involved intra-atrial pressure elevation), and LA dilation (the presence of a-IAB was more common in patients with larger atria) stands out. However, a-IAB relationship with a "documented" history of AF/flutter was not demonstrated, probably due to the diagnostic difficulty these arrhythmias entail if they are not permanent (although most part of persistent AFs, which accounted for $55 \%$ of all of them, and $100 \%$ of flutters belonged to group a-IAB). The fact that $90.9 \%$ (10 cases) of ischemic CVAs in the series (cardioembolic or of unknown cause) occurred in patients who had $a-I A B$ and barely in $9.1 \%$ of those who had $p$-IAB also stands out; of these 10 cases in the a-IAB group, $80 \%$ corresponded to stroke and $20 \%$ to transient ischemic attacks and, of all of them, only $40 \%$ had a previous history of documented AF or flutter. When the groups with $p-I A B$ and $a-I A B$ were compared using a bivariate analysis, only a-IAB was found to be related to a history of CVA ( $p=0.022)$, especially of stroke $(p=0.04)$.

Finally, a multivariate analysis was carried out (which included all three groups of patients and all variables shown in Table 1 with a $p<0.1$ ), which determined that the only variables related to the risk for developing a-IAB were being $\geq 65$ years of age (odds ratio $[\mathrm{OR}]=6.1$ ), diabetes mellitus $(\mathrm{OR}=6.1)$, diastolic dysfunction $(O R=6.0)$, and left atrial dilation $(O R=3.1)$ (Table 2).

The obtained results lead to conclude that the factors associated with the risk of suffering $a-I A B$ are being $\geq 65$ years old, diabetes, ventricular diastolic dysfunction, and dilated left atrium. Patients with a-IAB have a higher rate of ischemic CVA, especially stroke, which appears together with a history of AF or without it (either due to underdiagnosed arrhythmia or underlying atrial myopathy). These results highlight the possibility of AF screening and prevention and the need to specify whether patients with a-IAB should be anticoagulated to particularly prevent CVAs.

\section{Funding}

None.

\section{Conflicts of interest}

The authors declare that they have no conflicts of interest.

\section{Ethical disclosures}

Protection of human and animal subjects. The authors declare that no experiments were performed on humans or animals for this research.

Confidentiality of data. The authors declare that no patient data appear in this article.

Right to privacy and informed consent. The authors declare that no patient data appear in this article.

\section{References}

1. Bayés de Luna A, Platonov P, Cosío FG, Cygankiewicz I, Pastore C, Baranowski R. Interatrial blocks. A separate entity from left atrial enlargement: a consensus report. J Electrocardiol. 2012;45:445-51.

2. Hirsh B, Copeland-Halperin R, Halperin J. Fibrotic atrial cardiomyopathy, atrial fibrillation, and thromboembolism: mechanistic links and clinical inferences. J Am Coll Cadiol. 2015;65(20):2239-225.

3. Baranchuk A. Interatrial block and supraventricular arrhythmias. Clinical implications of Bayés' syndrome. Cardiotext. Minneapolis, Minnesota, USA, 2017. 
4. Martínez-Selles M, Fernández Lozano I, Baranchuck A, Bayés-Genis A Bayés de Luna A. Debemos anticoagular a pacientes en alto riesgo de sufrir fibrilación auricular? Rev Esp Cardiol. 2016;69:374-76.

5. Conde D, Baranchuk A. Bloqueo interauricular como sustrato anatómico-eléctrico de arritmias supraventriculares: síndrome de Bayés. Arch Cardiol Mex. 2014;84:32-40.

6. Baranchuk A, Enríquez A, Antiperovitch P, Alexander B, Cinier G. Advanced interatrial block as a key marker for atrial fibrillation recurrence: Bayés' syndrome. J Geriatr Cardiol. 2017;14:169-73.

7. Conde D, Seoane L, Gysel M, Mitrione S, Bayés de Luna A, Baranchuk A Bayés' syndrome: the association between interatrial block and supraventricular arrhythmias. Expert Rev Cardiovasc Ther. 2015;13:541-50.
8. Seoane L, Cortés M, Conde D. Update on Bayés' syndrome: the association between an interatrial block and supraventricular arrhythmias. Expert Review of Cardiovascular Therapy. 2019. DOI: 10.1080/14779072.2019. 1577137.

9. Escobar-Robledo LA, Bayés de Luna A, Lupón J, Baranchuk A, Moliner $\mathrm{P}$, Martínez- Sellés $\mathrm{M}$, et al. Advanced interatrial block predicts new-onset atrial fibrillation and ischemic stroke in patients with heart failure: the "Bayes syndrome-HF" study. Int J Cardiol. 2018;15;271: 174-80.

10. Arauz A, Arteaga C, Zapata-Gómez C, Ramos-Ventura C, Méndez B, Otiniano-Sifuentes $\mathrm{R}$, et al. Infarto cerebral embólico de origen no determinado: más allá de la fibrilación auricular. 2019. DOI: 10.1016/j.nrl.2019.03. 